\title{
Determination of urocanic acid, a compound implicated in histamine toxicity, and assessment of biogenic amines relative to urocanic acid content in selected fish and fish products
}

\begin{abstract}
The contents of trans- and cis-urocanic acid (cis-UCA), $\mathrm{NaCl}$ and moisture, and $\mathrm{pH}$ of sixtyseven fish and shrimp products, including salted anchovy, different types of salted fish, salted shrimp and shrimp paste collected in Malaysia, were examined. Included in the analysis was determination of the contents of nine biogenic amines. The average levels of trans- and cisUCA in salted anchovy, salted fish, salted shrimp and shrimp paste were 9.67 and 7.25, 14.2 and 11.0, 36.6 and 22.5, 6.96 and $18.7 \mathrm{mg} / \mathrm{kg}$, respectively. In general, the average levels of trans- and cis-UCA were much lower than the histamine levels in fish products. Results showed no strong correlation of $\mathrm{pH}$, salt and moisture contents with trans- and cis-UCA, nor with histamine. Biogenic amines were also detected in processed fish and shrimp products where the most abundant biogenic amine was putrescine with an average level of $227 \mathrm{mg} / \mathrm{kg}$ in shrimp paste. Thus, the high rates of cancers in consumers who consume dried salted fish could be indicative of the synergistic effects of biogenic amines and cis-UCA.
\end{abstract}

Keyword: Biogenic amines; Salt content; Moisture content; Trans-urocanic acid; Cisurocanic acid; Fish products; Shrimp products; Scombroid fish poisoning; Food safety; Food composition; Food analysis; Antinutrient; Regulatory trade issues in food; Compositional standards 